\title{
Rancang Bangun Sistem Pendingin Sekunder untuk Kabin Mobil dengan Memanfaatkan Thermoelectric (TEC)
}

\author{
J. Victor Tuapetel ${ }^{1, a)}$, A. Faishal Ramadhan ${ }^{2, b)}$, M. Kurniadi Rasyid ${ }^{3, c)}$ \\ 1, 2, 3 Program Studi Teknik Mesin ITI, \\ Jl. Raya Puspiptek Serpong, Tangerang Selatan-Banten, Indonesia, 15320 \\ a) jvictor.tuapetel@iti.ac.id, b) achmadfaisal43@gmail.com, ${ }^{\text {c) }}$ kurniadirasyid@iti.ac.id
}

\begin{abstract}
Abstrak
Sistem pendingin (AC) mobil tidak bekerja ketika mesin mobil dimatikan, hal ini menyebabkan suhu kabin mobil meningkat. Peningkatan suhu disebabkan oleh kabin yang tertutup sehingga tidak ada sirkulasi udara dan juga dipengaruhi oleh suhu lingkungan. Perancangan sistem pendingin pada penelitian ini bertujuan untuk mengkondisikan udara dalam kabin mobil. Perancangan, perakitan, dan pengujian sistem pendingin menggunakan peltier, kipas, heatsink, dan pompa sebagai komponen utamanya. Pengujian dilakukan untuk mengetahui metode pendinginan yang tepat untuk mereduksi panas yang dihasilkan peltier. Pada pengujian yang dilakukan selama 30 menit, diperoleh suhu pada cold sink menggunakan kipas sebesar $14.3^{\circ} \mathrm{C}$ dan suhu pada cold sink menggunakan coolant sebesar $10.3^{\circ} \mathrm{C}$. Pengujian pada sistem pendingin dilakukan selama 1 jam 30 menit, dengan variasi jumlah peltier yang bekerja yakni 2, 4 dan 6 . Hasil yang diperoleh yakni 2 peltier sebesar $28^{\circ} \mathrm{C}$, 4 peltier sebesar $26.5^{\circ} \mathrm{C}$, dan 6 peltier sebesar $27.5^{\circ} \mathrm{C}$. Hasil terbaik untuk metode pendinginan yaitu menggunakan coolant dan sistem pendingin menggunakan 4 buah peltier.
\end{abstract}

Kata kunci: peltier, pendingin sekunder, sistem pendingin mobil

\begin{abstract}
A car's cooling system does not work when the car's engine is turned off, this causes the car cabin temperature to rise. The increase in the temperature is caused by the cabin being closed so that there is no air circulation and is also influenced by the environment temperature. The cooling system design at this research aims to conditioning the air in the car cabin. The processes of designing, assembling, and testing the cooling system will be carried out with the use of peltier, fan, heatsink, and pump as the main components. Tests will be carried out to determine the appropriate cooling method to reduce the heat produced by peltier. The tests were carried out for 30 minutes on each tests, which yield the cold sink temperature using fan is $14.3^{\circ} \mathrm{C}$ and the cold sink temperature using coolant resulted is $10.3^{\circ} \mathrm{C}$. Tests on the cooling system were carried out for 1 hour 30 minutes, with variations in the number of working peltiers which is 2, 4 and 6. The results obtained were as follows, 2 peltiers is $28^{\circ} \mathrm{C}, 4$ peltiers is $26.5^{\circ} \mathrm{C}$, and 6 peltiers is $27.5^{\circ} \mathrm{C}$. The best results for the cooling method are obtained from using the coolant and 4 pieces of peltiers used for the cooling system.
\end{abstract}

Keywords: car cooling system, peltier, secondary cooling

\section{PENDAHULUAN}

Umumnya sistem pendingin mobil menggunakan refrigrant. Namun, refrigerant adalah bahan kimia yang dapat merusak lapisan ozon jika terurai di udara. Seiring dengan perkembangan teknologi sistem pendingin maka dapat dirancang sebuah sistem pendingin yang mampu mengkondisikan udara dalam kabin mobil meskipun mobil ditinggalkan dalam keadaan mesin mobil mati.

Teknologi termoelektrik merupakan sumber alternatif utama dalam menjawab permasalahan tersebut. Di samping lebih ramah lingkungan, teknologi ini sangat efisien, tahan lama, dan juga mampu menghasilkan energi dalam skala besar maupun kecil [1].

\section{LANDASAN TEORI}

\section{A. Termoelektrik}

Termolektrik merupakan konversi langsung dari energi panas menjadi energi listrik atau energi listrik menjadi energi panas atau dingin. Termoelektrik umumnya menggunakan bahan yang bersifat semikonduktor [2].

Struktur dari termoelektrik dapat dilihat pada Gambar 1 , terdiri dari suatu susunan elemen tipe-P, yakni material yang kekurangan elektron, dan terdiri juga dari susunan elemen tipe-N, yakni material yang kelebihan elektron. Panas masuk pada salah satu sisi dan dibuang dari sisi lainnya.

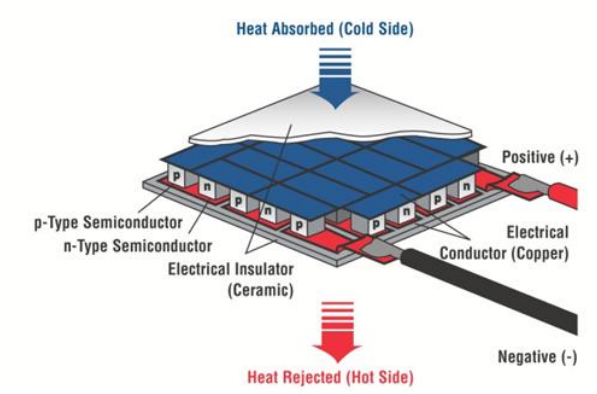

Gambar 1. Struktur Thermoelektrik

\section{B. Sel Peltier}

Konsep dari sel peltier yaitu efek Seebeck dan efek peltier, dimana sel peltier ini merupakan bahan semikonduktor yang bertipe-p dan tipe-n. Semikonduktor merupakan bahan setengah penghantar listrik yang disebabkan perbedaan gaya ikat diantara atom-atom, ionion, atau molekul-molekul.

C. Cara Kerja Peltier 
Apabila pada kedua konduktor yang berada di ujungujung untaian diberikan tegangan DC, maka arus listrik akan mengalir dari sumber tegangan yang berpotensial positif, melalui semikonduktor tipe $\mathrm{N}$ lalu ke semikonduktor tipe $\mathrm{P}$ hingga berakhir di sumber tegangan yang berpotensial negatif. Arah aliran elektron akan berkebalikan dengannya.

Efeknya adalah pada sisi atas terjadi pertemuan antara semikonduktor tipe $\mathrm{N}$ dan semikonduktor tipe $\mathrm{P}$ (melalui perantaraan logam konduktor) panas diabsorbsi sehingga pada bagian sisi atas dingin. Sedangkan di bagian sisi bawah panas.

\section{Konduktivitas Thermal}

Konduktivitas termal didefinisikan sebagai laju perpindahan panas per satuan luas yang tegak lurus pada aliran dan per satuan gradient suhu [3]. Dinyatakan dengan persamaan (1):

$$
K=\frac{Q}{A\left(\frac{d t}{d x}\right)}
$$

\section{E. Beban Panas Konduksi}

Pada pustaka [4] Beban panas konduksi adalah jumlah panas yang merambat akibat adanya perbedaan temperatur ruangan yang didinginkan dengan sekelilingnya, beban panas ini biasanya terjadi melalui permukaan dinding ruang pendingin. Besarnya beban panas konduksi dapat dihitung dengan persamaan (2) :

$$
Q k=U \cdot A \cdot \Delta t
$$

\section{METODE PENELITIAN}

Metode penelitian dilakukan berdasarkan diagram alir yang ditunjukkan pada Gambar 2 .

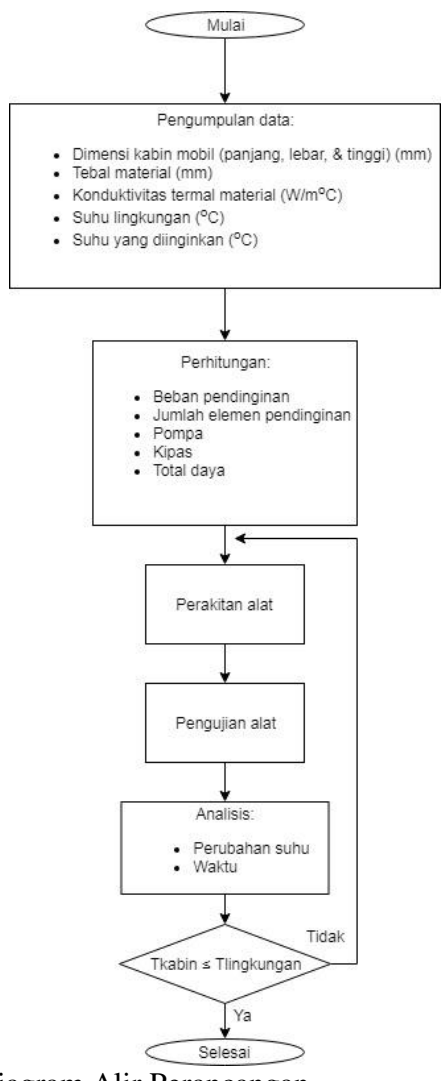

Gambar 2. Diagram Alir Perancangan

\section{HASIL DAN PEMBAHASAN}

A. Spesifikasi dan Data Awal

Sebagai dasar perhitungan rancang bangun sistem pendingin digunakan dimensi kabin mobil seperti pada Gambar 3.

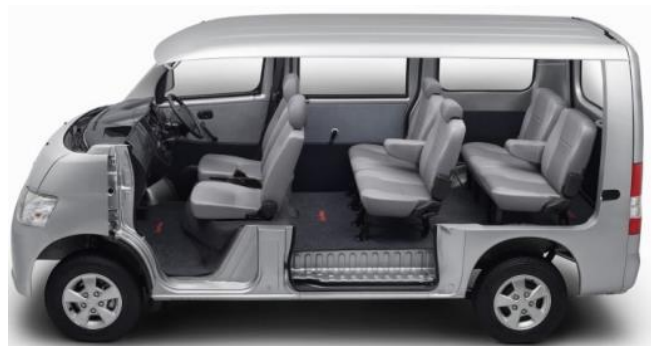

Gambar 3. Kabin Mobil

1. Dimensi kabin mobil
a. Panjang
: $3460 \mathrm{~mm}=3.46 \mathrm{~m}$
b. Lebar
$: 1665 \mathrm{~mm}=1.665 \mathrm{~m}$
c. Tinggi
: $1200 \mathrm{~mm}=1.2 \mathrm{~m}$

2. Konduktivitas thermal material
a. Kaca
: $0.8 \mathrm{~W} / \mathrm{m}^{\circ} \mathrm{C}$
b. Plat baja
: $50.2 \mathrm{~W} / \mathrm{m}^{\circ} \mathrm{C}$
c. Glass woll
: $0.05 \mathrm{~W} / \mathrm{m}^{\circ} \mathrm{C}$
d. Alumunium foil : $0.86 \mathrm{~W} / \mathrm{m}^{\circ} \mathrm{C}$
e. Plastik
: $0.039 \mathrm{~W} / \mathrm{m}^{\circ} \mathrm{C}$

3. Tebal material
a. Plat baja
$: 0.6 \mathrm{~mm}=0.0006 \mathrm{~m}$
b. Glass woll
$: 10 \mathrm{~mm}=0.01 \mathrm{~m}$
c. Alumunium foil
d. Plastik
$: 1 \mathrm{~mm}=0.001 \mathrm{~m}$
e. Kaca
$: 2 \mathrm{~mm}=0.002 \mathrm{~m}$
$: 6 \mathrm{~mm}=0.006 \mathrm{~m}$

4. Suhu lingkungan $: 34^{\circ} \mathrm{C}$

5. Beban Pendinginan

Beban pendinginan yang diperoleh merupakan beban dari lingkungan melalui atap, pintu, bagasi dan kaca mobil. Besarnya beban pendinginan dapat dihitung dengan persamaan (1) sebagai berikut:

$$
\mathrm{Q}=\mathrm{A} \cdot \mathrm{U} \cdot \Delta \mathrm{t}
$$

Dimana $\mathrm{U}_{\text {body }}=2.47 \mathrm{~W} / \mathrm{m} 2{ }^{\circ} \mathrm{C}$

a. Q bodi mobil

1) Qatap

$=\mathrm{A} \cdot \mathrm{U} \cdot \Delta \mathrm{t}$

$=(3.1 .665) \cdot 2.47 \cdot(34-27)$

$=86.36 \mathrm{Watt}$

2) Qbelakang

$=\mathrm{A} \cdot \mathrm{U} \cdot \Delta \mathrm{t}$

$=[(1.665 .1 .2)-(1.33 .0 .5)] \cdot 2.47 .(34-27)$

$=23.14 \mathrm{Watt}$

3) Qsamping

$=2 \cdot \mathrm{A} \cdot \mathrm{U} \cdot \Delta \mathrm{t}$

$=2[(3.46 .1 .2)-(2.490 .0 .5)] \cdot 2.47 .(34-27)$

$=100.52 \mathrm{Watt}$

4) Q Total

Qatap + Qbelakang + Qsamping = 210.02 Watt

b. Q kaca mobil

1) Qk.depan

$=\mathrm{A} \cdot \mathrm{U} \cdot \Delta \mathrm{t}$ 
$=(1.5 .0 .5) .6 .549 .(34-27)$

$=34.37 \mathrm{Watt}$

2) Qk.samping

$$
\begin{aligned}
& =2 \mathrm{~A} \cdot \mathrm{U} \cdot \Delta \mathrm{t} \\
& =2(2.49 \cdot 0.5) \cdot 6.549 \cdot(34-27) \\
& =114.14 \text { Watt }
\end{aligned}
$$

3) Qk.belakang

$$
\begin{aligned}
& =\mathrm{A} \cdot \mathrm{U} \cdot \Delta \mathrm{t} \\
& =(1.33 \cdot 0.5) \cdot 2.73 \cdot(34-27) \\
& =30.47 \text { Watt }
\end{aligned}
$$

4) Q Total

Qk.depan + Qk.samping + Qk.belakang = 178.98 Watt

6. Jumlah Elemen Pendingin

Termoelektrik yang digunakan pada pendingin kabin adalah termoelektrik dengan tipe TEC112706 dengan spesifikasi:

$\begin{array}{ll}\text { Dimensi } & : 40 \times 40 \times 3.8 \mathrm{~mm} \\ \text { I maksimum } & : 6.0 \mathrm{~A} \\ \text { V maksimum } & : 15.4 \mathrm{~V}-\mathrm{DC} \\ \text { Q maksimum } & : 65 \mathrm{~W} \\ \text { T maksimum } & : 68 \text { degree }\end{array}$

Oleh karena itu untuk mendinginkan kabin mobil diperlukan peltier dengan jumlah sebagai berikut:

$\frac{Q_{t} \text { bodi mobil }+Q_{t} \text { kaca mobil }}{P \text { poltier }}$

$$
210.02+178.98 \quad 6 \text { buah }
$$

7. Pemilihan Kipas

$$
65
$$

Guna mendapatkan pendinginan yang optimal diperlukan kipas yang berfungsi untuk menghembuskan udara dingin yang dihasilkan oleh elemen peltier. Spesifikasi kipas terpilih sebagai berikut:

$\begin{array}{ll}\text { Dimensi } & : 93 \times 90 \times 60 \mathrm{~mm} \\ \text { Tegangan } & : 12 \mathrm{~V}-\mathrm{DC} \\ \text { Daya } & : 3.2 \mathrm{~W} \\ \text { Kecepatan Putaran } & : 2200 \mathrm{rpm}\end{array}$

8. Pemilihan Pompa

Peltier memiliki sisi yang dapat menghasilkan panas, apabila panas itu tidak diserap maka proses pendinginan tidak berlangsung dengan optimal. Oleh karena itu diperlukan pendingin yang mampu menyerap panas yang dihasilkan oleh peltier. Dalam rancangan sistem pendingin ini yang berfungi untuk menyerap adalah air/fluida, dimana nanti fluida ini akan mengalir di water block yang menempel pada sisi panas peltier. Spesifikasi pompa:

$$
\begin{array}{ll}
\text { Dimensi } & : 55 \times 35 \times 45 \mathrm{~mm} \\
\text { Daya Maksimum } & : 3.6 \mathrm{~W} \\
\text { Tegangan } & : 12 \mathrm{~V}-\mathrm{DC} \\
\text { Head Maksimum } & : 3 \mathrm{~m}
\end{array}
$$

\section{B. Proses Pembuatan}

Pertama, yang dilakukan adalah pembuatan body atau box sistem pendingin seperti pada Gambar 4. Material yang digunakan untuk membuat box adalah akrilik dengan ketebalan $10 \mathrm{~mm}$, dan untuk dudukan yang menghubungkan peltier dan waterblock menggunakan plat alumunium dengan ketebalan $3 \mathrm{~mm}$.

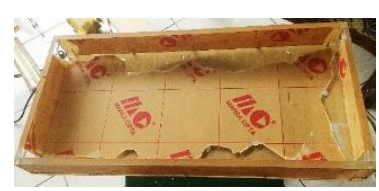

(a)

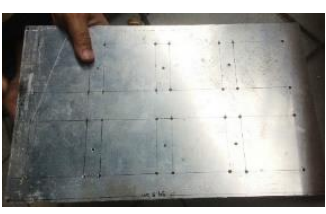

(b)
Gambar 4. (a) Body akrilik (b) Dudukan alumunium

Kedua, membuat waterblock seperti pada Gambar 5. Waterblock ini berfungsi sebagai media untuk mengalirkan air guna menyerap panas yang dihasilkan oleh peltier. Material yang digunakan untuk membuat waterblock adalah alumunium profile. Dimana pada kedua sisinya akan ditutup menggunakan lem karet dan sebagai saluran keluar masuk airnya menggunakan pipa plastik berdiameter $3 \mathrm{~mm}$.

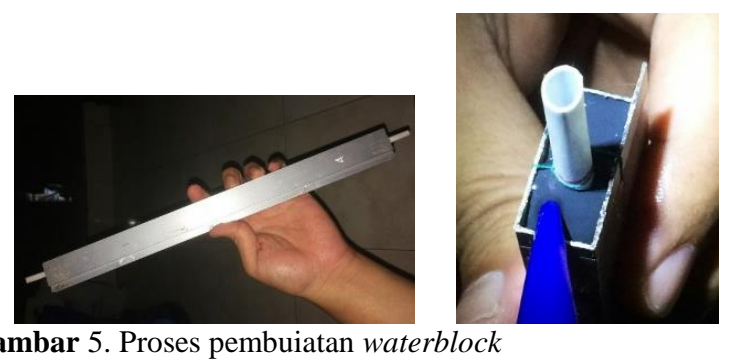

Ketiga, membuat reservoir seperti pada Gambar 6, reservoir ini berfungi sebagai media penampungan air. Material yang digunakan adalah akrilik dengan ketebalan $5 \mathrm{~mm}$. Di dalam reservoir dipasang cold sink, pemasangan cold sink ini diharapkan mampu untuk mendinginkan kembali air yang telah mengalir dari waterblock.
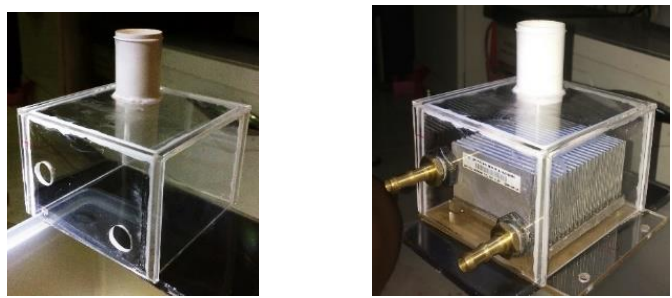

Gambar 6. Proses pembuatan reservoir

Keempat, merakit sistem pendingin seperti pada Gambar 7. Proses perakitan diawali dengan menyatukan waterblock dengan base alumunium, kemudian waterblock diberi pasta thermal, yang bertujuan agar panas dapat didistribusikan dengan baik

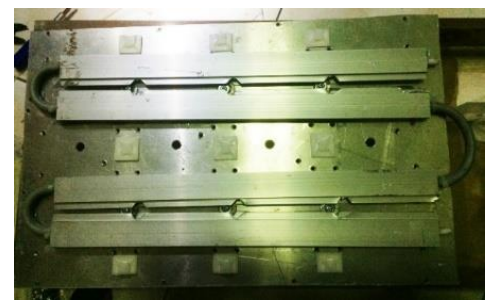

Gambar 7. Perakitan waterblock 
Kelima, adalah merakit peltier seperti pada Gambar 8. Dimana heatsink dan kipas diletakan pada dudukan alumunium. Pada sisi panas dan sisi dingin peltier diberi pasta termal.

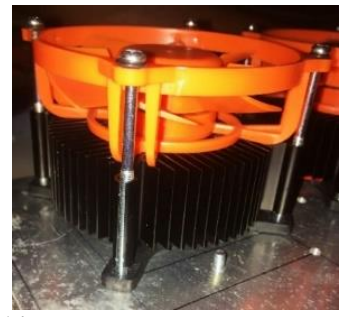

Gambar 8. Perakitan kipas

\section{Pengujian Dan Analisis}

Pengujian dilakukan untuk mengetahui metode pendinginan yang tepat, pengujian dilakukan selama 30 menit dengan menggunakan kipas dan coolant. Hasil pengujian ditunjukkan pada tabel 1 .

Tabel 1. Perubahan suhu peltier menggunakan kipas

\begin{tabular}{ccc}
\hline Komponen Sistem Pendingin & $\begin{array}{c}\text { Waktu } \\
(\mathbf{m e n i t})\end{array}$ & $\begin{array}{c}\text { Suhu } \\
\left({ }^{\mathbf{o}} \mathbf{C}\right)\end{array}$ \\
\hline & 0 & 30 \\
& 5 & 15.7 \\
$\mathrm{~T}_{\text {Peltier }}$ & 10 & 14.1 \\
& 15 & 15.7 \\
& 20 & 15.5 \\
& 25 & 15.6 \\
& 30 & 15.4 \\
\hline
\end{tabular}

Pengujian berikutnya menggunakan coolant sebagai metode pendinginan sisi panas peltier. Hasil pengujian ditunjukkan pada tabel 2 .

Tabel 2. Perubahan suhu peltier menggunakan coolant

\begin{tabular}{ccc}
\hline Komponen Sistem Pendingin & $\begin{array}{c}\text { Waktu } \\
\text { (menit) }\end{array}$ & $\begin{array}{c}\text { Suhu } \\
\left({ }^{\circ} \mathbf{C}\right)\end{array}$ \\
\hline & 0 & 30 \\
& 5 & 1.8 \\
\multirow{2}{*}{$\mathrm{T}_{\text {Peltier }}$} & 10 & 1.6 \\
& 15 & 1.3 \\
& 20 & -1 \\
& 25 & -2.5 \\
& 30 & -2.5 \\
\hline
\end{tabular}

Hasil pengujian dengan metode pendinginan sisi panas peltier menggunakan kipas, didapatkan suhu maksimal $15.4^{\circ} \mathrm{C}$, sedangkan menggunakan coolant didapatkan suhu maksimal $-2.5^{\circ} \mathrm{C}$.

Dari Gambar 9 menunjukkan adanya perbedaan yang cukup jauh antara menggunakan kipas dan coolant. Hal ini dapat disimpulkan bahwa pendinginan sisi panas peltier menggunakan coolant lebih baik.

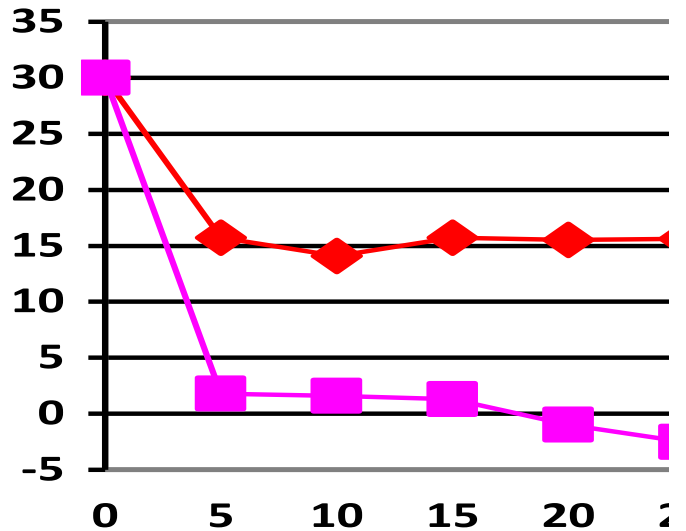

Gambar 9. Grafik metode pendinginan sisi panas peltier

Pengujian sistem pendingin dilakukan dengan 3 variasi jumlah peltier yang bekerja. Variasi jumlah peltier untuk mengetahui kemampuan pendinginan dari sistem pendingin, Variasi yang dilakukan :

a. 2 buah peltier yang bekerja

b. 4 buah peltier yang bekerja

c. 6 buah peltier yang bekerja

Pengujian dilakukan secara tiga tahap dengan daya baterai $12 \mathrm{~V}, 3 \mathrm{~A}$. Tahap pertama yaitu menguji pendinginan menggunakan 2 buah peltier dengan suhu lingkungan $29.5^{\circ} \mathrm{C}$ dan suhu dalam kabin $30^{\circ} \mathrm{C}$. Pengujian dilakukan selama 1 jam 30 menit. Hasil pengujian ditunjukkan pada tabel 3 .

Tabel 3. Hasil pengujian variabel tahap pertama

\begin{tabular}{llc}
\hline No. & Waktu & Temperatur $\left({ }^{\mathbf{0}} \mathbf{C}\right)$ \\
\hline 1. & 14.30 & 30 \\
2. & 14.45 & 29.8 \\
3. & 15.00 & 29.5 \\
4. & 15.15 & 29 \\
5. & 15.30 & 28.6 \\
6. & 15.45 & 28.3 \\
7. & 16.00 & 28 \\
\hline
\end{tabular}

Tahap kedua yaitu menggunakan 4 buah peltier yang bekerja dengan suhu lingkungan $30^{\circ} \mathrm{C}$ dan suhu dalam kabin mobil $30.8^{\circ} \mathrm{C}$. Pengujian dilakukan selama 1 jam 30 menit. Hasil pengujian ditunjukkan pada tabel 4.

Tabel 4. Hasil pengujian variabel tahap kedua

\begin{tabular}{llc}
\hline No. & Waktu & Temperatur $\left({ }^{\mathbf{0}} \mathbf{C}\right)$ \\
\hline 1. & 14.30 & 30 \\
2. & 14.45 & 29.4 \\
3. & 15.00 & 29 \\
4. & 15.15 & 28.7 \\
5. & 15.30 & 28.2 \\
6. & 15.45 & 27.5 \\
7. & 16.00 & 26.5 \\
\hline
\end{tabular}

Tahap ketiga menggunakan 6 buah peltier yang bekerja 3 dengan suhu lingkungan $28.9^{\circ} \mathrm{C}$ dan suhu dalam kabin mobil $30^{\circ} \mathrm{C}$. Pengujian dilakukan selama 1 jam 30 menit. Hasil pengujian ditunjukkan pada tabel 5. 
Tabel 5. Hasil pengujian variabel tahap ke tiga

\begin{tabular}{llc}
\hline No. & Waktu & Temperatur $\left({ }^{\mathbf{0}} \mathbf{C}\right)$ \\
\hline 1. & 18.30 & 30 \\
2. & 18.45 & 29.3 \\
3. & 19.00 & 28.8 \\
4. & 19.15 & 28.4 \\
5. & 19.30 & 28.6 \\
6. & 19.45 & 28.3 \\
7. & 20.00 & 27.5 \\
\hline
\end{tabular}

Hasil pengujian dengan tiga variasi dengan 2 buah peltier yang bekerja diperoleh hasil $28^{\circ} \mathrm{C}, 4$ buah peltier yang bekerja diperoleh hasil $26.5^{\circ} \mathrm{C}$, dan untuk 6 peltier diperoleh hasil $27.5^{\circ} \mathrm{C}$. Didapatkan kesimpulan bahwa jumlah peltier dapat mempengaruhi proses pendinginan akan tetapi semakin banyak peltier yang bekerja tegangan yang dialirkan pun mengecil.

Dari Gambar 10 dapat dilihat bahwa pengujian memperlihatkan trend penurunan suhu. Namun pada pengujian menggunakan 6 peltier dapat dilihat bahwa terjadi kenaikan suhu setelah 45 menit beroperasi, lalu kembali turun. Sementara pengujian dengan 4 peltier menunjukan penurunan suhu yang signifikan.

$\mathrm{T}$

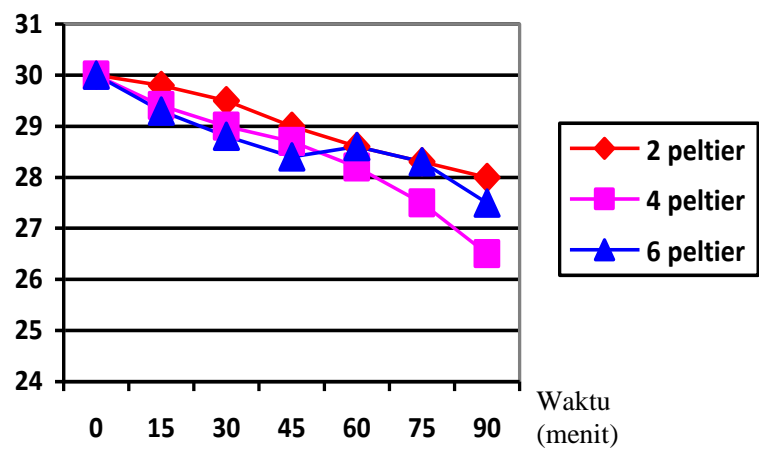

Gambar 10. Grafik hasil pengujian variabel tahap pertama, kedua dan ketiga

\section{KESIMPULAN}

1. Hasil pengujian untuk 2 buah peltier $28^{\circ} \mathrm{C}, 4$ buah peltier $27.5^{\circ} \mathrm{C}$ dan 6 buah peltier $27.5^{\circ} \mathrm{C}$. penggunaan 4 dan 6 buah peltier mendapatkan hasil yang sama akan tetapi pada 6 buah peltier terjadi kenaikan suhu, sehingga dapat disimpulkan bahwa pendinginan yang baik yaitu menggunakan 4 buah peltier.

2. Dibutuhkan sebuah baterai yang memiliki daya yang besar untuk mengoptimalkan sistem pendingin.

3. Kemampuan pendinginan peltier dipengaruhi oleh proses pendinginan pada sisi panas yang dikeluarkan

4. peltier, karena apabila panas tersebut tidak di serap atau didinginkan maka kinerja peltier tidak akan optimal.

\section{REFERENSI}

[1] Nugroho, Wahyu. Rancang Bangun Alat Pendingin Minuman Portable Menggunakan Peltier. Skripsi. Jurusan
Teknik Mesin. Fakultas Teknik. Universitas Muhammadiyah Pontianak, 2016.

[2] A. Fitra Indra. Studi Penggunaan Modul Thermoelektrik Sebagai Sistem Pendingin Portable. Kendari. Jurnal Ilmiah Mahasiswa Teknik Mesin 1(1): 50-55.

[3] Ahsani Munib. Rancang Bangun Pendingin Ruangan Portable Dengan Memanfaatkan Efek Perbedaan Suhu Pada Thermoelectric Cooler. Surabaya. Jurnal Rekayasa Mesin 3 (1): 100-109.

[4] Dermawan Erwin, Syawaludin, A. Reza, dkk. Analisa Perhitungan Beban Kalor Dan Pemilihan Kompresor Dalam Perancangan Air Blast Freezer Untuk Membekukan Adonan Roti Dengan Kapasitas 250 $\mathrm{Kg} / \mathrm{Jam}$. Jakarta. Teknika: Engineering and Sains Journal, 1 (2): 141-144. 